\title{
Gastrointestinal sistem kanserlerinin evrelemesinde endoskopik ultrasonografi
}

\author{
Endoscopic ultrasonography in cancer staging for gastrointestinal malignancies
}

Mehmet BEKTAŞ ${ }^{1}$, Manoop S BHUTANI ${ }^{2}$

Ankara Üniversitesi Tip Fakültesi, ${ }^{1}$ Gastroenteroloji Bilim Dall, Ankara

The University of Texas, MD Anderson Cancer Center Department of ${ }^{2}$ Gastroenterology, Hepatology and Nutrition Houston, Texas, USA

Endoskopik ultrosonografi, barsak duvarının tüm katmanlarının ve barsak çevresi lenf nodlarnn gösterebilmesi nedeniyle gastrointestinal sistem kanserlerinin evrelemesinde kilit rol oynar. Endoskopik ultrosonografi ile kanser evrelemesi; bilgisayarl tomografi, pozitron emisyon tomografi ve bilgisayarl tomografi veya manyetik rezonans görüntüleme de uzak metastaz saptanmayan olgularda endikedir. Endoskopik ultrosonografi ile gastrointestinal sistem kanserlerinin evrelemesinde tümör - nod - metastaz sinıflaması kullanılır Yaklaşık olarak bütün gastrointestinal sistem kanserlerinde T evrelemesinde endoskopik ultrosonografinin tanısal doğruluk oranı \%85, N evrelemesinde ise doğruluk oranı \% 75'dir. Kanserlerin doğru evrelenmesi önemlidir çünkü; prognoz hakkında bilgi sağlar ve tedaviye yön verebilmektedir. Ek olarak endoskopik ultrosonografi yardımıyla malign görünümdeki lenf nodlarından iğne aspirasyonu yapılır ve bu sayede $N$ evrelemesinin tanısal doğruluğu artar.

Anahtar kelimeler: Endoskopik ultrasonografi, kanser evrelemesi, gastrointestinal sistem kanserleri

\section{GIIRISŞ}

Endoskopik ultrasonografi (EUS); gastointestinal sistem (GIS) kanserleri, bronkojenik ve/veya mediastinal kanserlerinin evrelemesinde yaklaşık 20 yıldan fazla süredir kullanılan tanısal doğruluk oranı yüksek bir yöntemdir (1). Günümüzde radyolojideki yoğun gelişmeler sonucu bilgisayarlı tomografi (BT), pozitron emisyon tomografi ve bilgisayarl tomografi (PETBT) ve EUS ve EUS klavuzluğunda ince iğne aspirasyonu (EUS-FNA) özofagus, mide ve rektum gibi GIS kanserlerinin evrelemesindeki algoritmde yer alır. EUS, GIS kanserlerinin lokal evrelemesinde etkin ve güvenilir olup kanserin prognozu hakkında bilgi verir ve tedaviye yol gösterir (1). EUS ile özofagus kanserlerinde evreleme, BT/PET-BT ve manyetik rezonans görüntüleme (MRI) ile uzak metastaz dışlandıktan sonra yapilır. EUS ile kanser evrelemesinde tümör - nod metastaz (TNM) siniflaması kullanılır $(2,3)$. Bu siniflamaya göre Tl evresi Tlm ve Tlsm diye ikiye ayrilır. uTlm: Lamina propria ve/veya muskularis mukoza invazyonunu; uTlsm ise submukozal invazyonunu gösterir. uT2: Muskularis propriya invazyonu; uT3: Adventisia/seroza invazyonu ve uT4: komşu veya diğer organ invazyonunu gösterir.

EUS'un barsak duvarı, barsak çevresi lenf bezlerini ve komşu organları da iyi gösterebilmesi nedeniyle de pankreas kanser-
Endoscopic ultrasonography has gained a pivotal role in cancer staging for gastrointestinal malignancies because of its ability to image both the layers of the intestinal wall and peri-intestinal lymph nodes and organs. Endoscopic ultrasonography should be used after computerized tomography, positron emission tomography scanning or magnetic resonance imaging scan has shown no distant metastatic disease. The TNM classification is used for gastrointestinal system cancer staging with endoscopic ultrasonography. Endoscopic ultrasonography staging accuracy is applicable to all luminal gastrointestinal tract cancers, with an approximate T-stage accuracy of $85 \%$ and $\mathrm{N}$-stage accuracy of $75 \%$. Accurate cancer staging is needed because it provides prognostic information and guides treatment. Additionally, endoscopic ultrasonography fine-needle aspiration can be used to biopsy any malignantappearing lymph nodes, and it slightly increases the N-stage accuracy.

Key words: Endoscopic ultrasonography, cancer staging, gastrointestinal system cancer

leri, safra kesesi ve safra yolları kanserlerinin lokal evrelemesinde kullanılır. GİS duvarı EUS işlemi sırasında beş tabaka halinde görüntülenir. Bu tabakaların eko yapısı hiperekoik veya hipoekoiktir. 1. Superfisiyal mukoza (Hiperekoik), 2. Derin mukoza (Hipoekoik), 3. Submukoza ( Hiperekoik), 4. Muskularis Propria (Hipoekoik), 5. Seroza (Hiperekoik) (Figür 1). Bu beş tabaka genel olarak tüm GIS boyunca gözlenir. GIS kanserleri invazyon derinliklerine göre: erken evre [mukoza (Tm) ya da submukoza (Tsm) tutulmuş ancak lenf nodu metastazı yok] ve ileri evre (muskularis propria ve daha derine invazyon mevcut) olarak ikiye ayrilır. Erken evre kanserlerin tanısında yüksek frekanslı kateter problar (mini prob) kullanılır. Mini problar $2.8 \mathrm{~mm}$ kanallı standart endoskopların içinden geçerler. 12-20-30 MHz gibi değişik tiplerde olup ya su immersiyonlu veya balonludurlar. Bunların çözünürlükleri çok iyi olup, mukoza ve submukoza ayrımını net yaparlar; ancak penetrasyon derinlikleri düşük olması nedeniyle çevre lenf nodları göstermede yetersizdir. Mini prob cihazlarla GIS duvarı 7 ile 9 tabaka olarak görüntülenir. Ilk 4 tabaka Mukoza (1 ve 2. tabaka: epitel, 3. tabaka: lamina propria, 4. tabaka: muskularis mukoza), 5. tabaka: Submukoza, 6-7. tabaka: Muskularis propria (6. tabaka: iç sirküler kas, 7. tabaka: dış longitudinal kas) ve 8. tabaka: serozadır. 


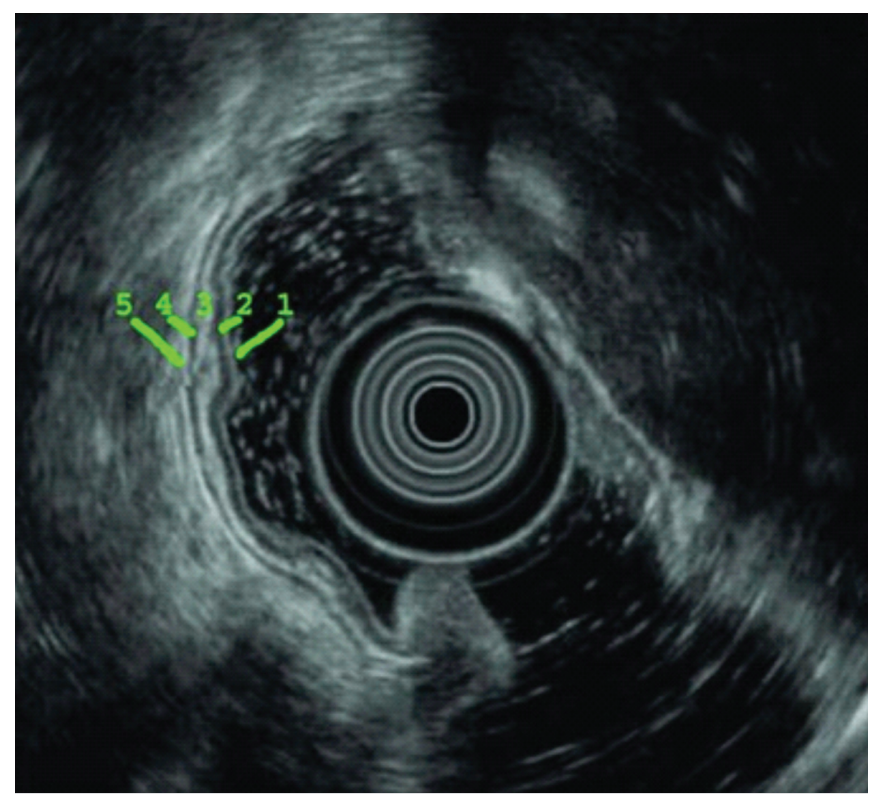

Figür 1. Radial EUS ile mide duvarının 5 tabaka halinde görünümü. 1 . Süperfisiyal mukoza: Hiperekoik, 2. Muskularis mukoza: Hipoekoik, 3. Submukoza: Hiperekoik, 4. Muskularis propria: Hipoekoik, 5. Seroza: Hiperekoik.

\section{A. ÖZOFAGUS KANSERLERINIIN EVRELEMESINDE EUS}

Özofagus kanserlerinde hastanın yaşam süresi kanserin evresine bağlı olup ortalama 5 ylllık yaşam \%10-20'dir. Evreleme için önce uzak metastazları ekarte etmek amaciyla BT veya PET-BT kullanılır. Eğer bu yöntemlerde uzak metastaz saptanmaz ise EUS yapılır. Özofagus kanseri evrelemesinde TNM sinıflaması kullanılır. Distal özofagus kanserlerinde üst torasik lenf nodu ve çöliyak lenf nodu tutulumu Mla, özofagogastrik bileşke kanserlerinde ise sol gastrik ve çöliyak lenf nodları tutulumu N1 kabul edilir. Lenf nodu metastazı olamayan T1 ve T2 olgulara operasyon uygulanırken; T3/T4 N1 olgulara kemoradyoterapi, takiben yeniden evreleme ve arkasindan eğer uygun ise operasyon önerilir (4). Özofagus kanserli hastaların başvuru anında çoğunluğu T3 evresindedir ve lenf nodu metastazı \% 77'sinde saptanır. Erken evre ya da T1 evre tümörler; Tla (Tlm) ve Tlb (Tlsm) diye ikiye ayrllır, Tla mukozada sinırlı iken Tlb'de submukozaya invazyon söz konusudur. Endoskopik rezeksiyon düşünülen vakalarda bu ayrım mutlaka yapılmalıdır. Tam bir görüş birliği olmamakla birlikte tümör çevresinde 1-2 lenf nodu varlı̆̆ $\mathrm{N1}$, >3 lenf nodu varlığı ise N2 kabul edilir.

\section{İşlemin Yapılışı}

İslem sırasında önce tümörün yerleşim yeri belirlenir, eğer darlık yok ve ekoendoskop rahat geçiyor ise mideye ilerlenir. Daha sonra cihaz geri çekilerek tümörün özofagus duvarına invazyon derinliği, aortun tutulumu, peritümöral lenf nodları, çölyak lenf nodu ve karaciğer metastazı araştırılır. Radial ve lineer cihaz ile lenf nodu ve tümor evrelemesinde fark yoktur. 104 hastalık bir seride tümor ve lenf nodu evrelemesinde her iki cihaz arasinda fark bulunmaz iken; başka bir çalışmada ise lenf nodunu saptamada elektronik radial ekoendoskobun; lineer ekoendoskoptan üstün olduğu rapor edilmiştir $(5,6)$. Eğer tümöre bağlı darlık söz konusu ve ekoendoskop ile geçilemiyorsa lineer cihaz burada radial ekoendoskopa göre daha yararlıdır. Özofagus kanserlerinin doğru evrelemesinde kişinin tecrübesi de önemlidir. Doğru evreleme için en az 75100 muayene yapılmış olmalıdır.

\section{Erken Özofagus Kanserlerinde EUS}

Erken özofagus kanseri tanım olarak lenf nodu tutulumu olmayan mukoza ya da submukozada sinırl kanserlere denir. Lenf nodu metastazı mukozal kanserlerde \%3, submukozal kanserlerde ise \%20-30 arasındadır. 7.5 MHz ve $10 \mathrm{MHz}$ ekoendoskoplar erken özofagus kanserlerinin değerlendirilmesinde kullanılmakla birlikte; çözünürlükleri düşük olup \%25 olguda yanlış evrelemeye neden olmaktadır. Bu yüzden erken özofagus kanserlerinin evrelemesinde yüksek frekanslı (20-30 $\mathrm{MHz}$ ) kateter problar kullanılır. Erken özofagus kanserlerinde mini prob ultrasonografinin tanısal doğruluk oranı \%61 ile \%95 arasında rapor edilmiştir (7). Japonya gibi uzak doğudan yapılan çalışmalarda erken özofagus kanserlerinin değerlendirilmesinde mini prob'un doğruluk oranı \%93 iken; Avrupa ve Amerika gibi batı ülkelerinde ortalama oran $\% 76$ bildirilmiştir (8-14). Ayrıca özofagusun anatomisinden dolayı üst ve orta özofagus erken kanserlerinin mini prob ile değerlendirmesi daha kolay olup doğru evreleme oranı yüksek iken (\%8793); özofagogastrik bileşke yerleşimlilerde ise düşüktür (\%48-69) $(11,13)$.

Erken özofagus kanserlerinin evrelemesinde su immersiyonlu mini prob ile balon mini prob arasında tanısal doğruluk oranı açısından fark olmadığı söylenmektedir. Su immersiyonlu sisteme sahip olanların işlem sırasında çift kanallı endoskop kullanılması önerilmektedir. Esaki ve arkadaşları 40 hastayı randomize etmişler. 18 vakaya balon mini prob, 22 olguyada su immersiyonlu mini prob kullanmışlar. Özellikle epitel ve lamina propria invazyonunu göstermede balon mini probun su immersiyonlu mini propdan daha sensitif olduğunu (sirasiyla \%100 vs \%50) saptamışlar (15).

Özofagus Kanserlerinde EUS ile Tümor ve Lenf Nodu Evrelemesi

EUS ile özofagus kanseri evrelemesinde TNM sinıflaması kullanılır (Fgür 2). 1986-2005 arası 43 çalışmanın sonuçlarını gösteren bir meta-analizde T evresi için doğruluk oranı \%8192 bulunmuş. Bu oran ileri evrede (T3-T4) \%92; erken evrede (T1-T2) \%81 saptanmış (19). Lenf nodu evrelenmesinde ise EUS'un tanısal doğruluk oranı \%77, sensitivitesi \%81, spesifitesi ise \%73 rapor edilmiştir. Tanısal doğruluk oranı hem BT ile hem de PET-BT evrelemelerde EUS'dan daha dü- 

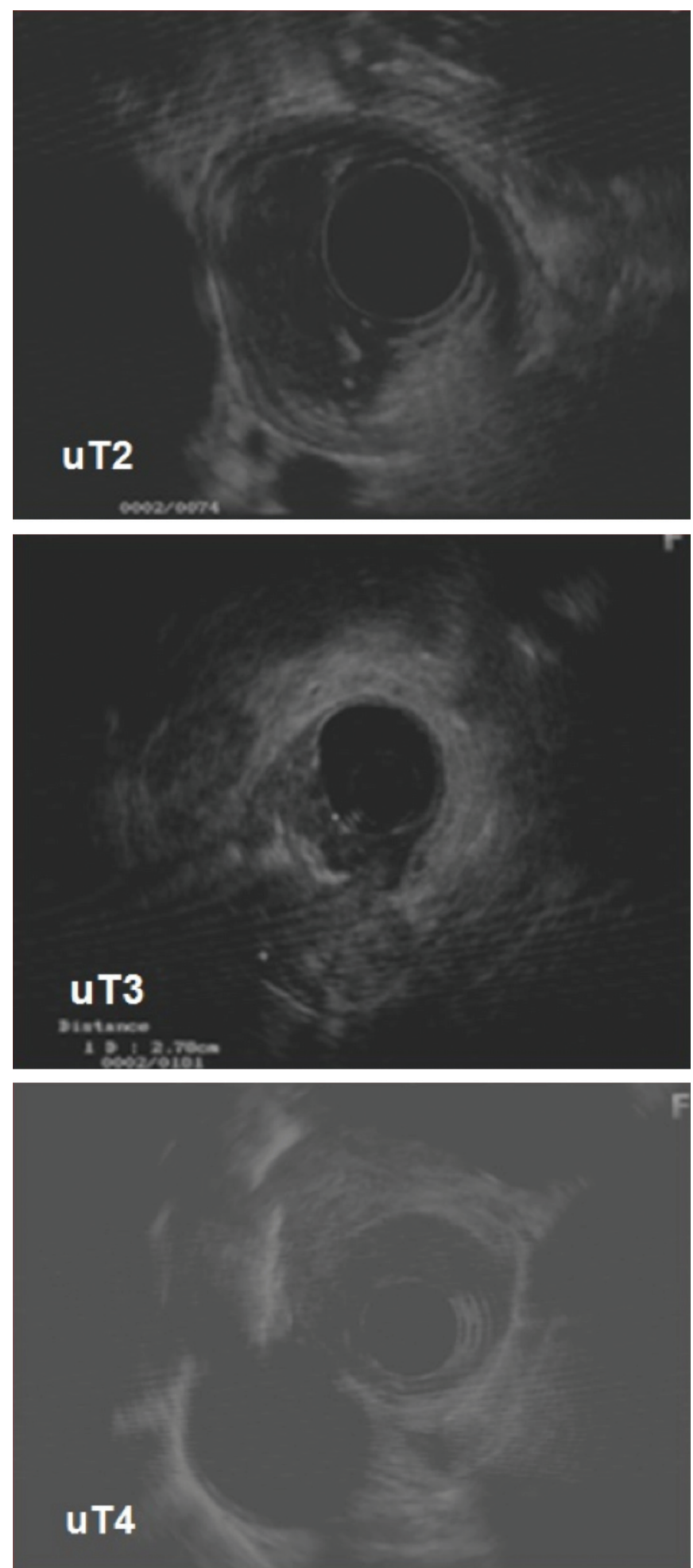

Figür 2. Özofagus kanserinin EUS ile evreleme görüntüleri. uT2: muskularis propria invazyonu, uT3: Adventisia invazyonu, uT4: Aorta invazyonu

şük bulunmuştur (sırasıyla; \%65 ve \%69) (16). EUS literatüründe malign lenf nodunun tanımlaması: lenf bezinin kısa aksı $10 \mathrm{~mm}$, yuvarlak, sınırları düzgün -keskin ve hipoekoik görünümde olmasıdır (17). Bu dört kriteri karşılayan lenf nodlarında malignite için sensitivite \%80-100'dür, buna kar- șın malign lenf nodlarının sadece \% 25 'i bu dört kritere sahiptir $(17,18)$. Tümöre komşu olan, yuvarlak ve hipoekoik lenf nodları EUS yapan kişiler tarafından genellikle malign kabul edilir. Lenf nodu sayısının çokluğunun prognozla ters ilişkili olduğu gösterilmiştir. EUS ile T evrelemesindeki temel sorun; var olan tümörün olduğundan daha ileri veya daha erken evre olarak yorumlanmasıdır. EUS, peritümöral inflamasyon ile tümör ayrımını yapamaz. Bu yüzden olgularda genellikle olduğundan daha ileri evre yorumlama hatası yapilır. Özofagus darlığı olan olgularda ise tümör distaline geçilemediğinden mikroskopik tümör invazyonu gösterilemez ve daha düşük evre olarak rapor edilir. Lenf nodu evrelemesindeki kisitlama ise genellikle lenf nodunun morfolojik görünümüdür. Ayrıca tümöre bağlı darlığı olanlarda periözofageal lenf nodları ve çölyak lenf nodu görüntülenemeyebilir.

\section{Lenf Nodundan EUS Eşliğinde Biyopsi (EUS- FNA)}

EUS işlemine EUS-FNA'in ilave edilmesi tanısal doğruluk oranını artırır. EUS-FNA ile lenf nodu evrelemesi için iki ayrı meta-analiz çalıșmasında sensitivite \%80-85, spesifite ise \%70-85 bildirilmiștir $(16,19,20)$. EUS ile EUS-FNA'in özofagus kanserinde evrelemeye etkisini doğrudan araştıran yeterli sayıda karşılaştırmalı çalışma yoktur. Sadece 76 hastalık bir çalışmada bu iki yöntem karşılaştırılmış ve tek başına EUS yapılan hastalarda lenf nodu metastazı oranı \%74 iken; EUS/EUS-FNA yapılanlarda \%87 bulunmuș $(\mathrm{p}=0.012)$. Ayr1ca bu çalıșmada; hem tek bașına EUS, hem de EUS +EUSFNA helikal BT'ye üstün bulunmuş (4). EUS eşliğinde trans özofageal lenf nodu aspirasyonu malign görünümdeki lenf nodlarından ve çöliyak lenf bezlerinden yapılır. Her lenf bezi biyopsisi için farklı iğne kullanılarak tümör hücrelerinin yayılımı önlenir. EUS eşliğinde çöliyak lenf nodu biyopsileri tedaviyi değiştirir ve lenf nodunun pozitif gelmesi inoperabıl olduğunu gösterir. Buna karşın alınan biyopsi örneğinin negatif gelmesi de tümör olmadığı anlamına gelmez. \%7 oranında peri-özofageal lenf nodlarından alınan biyopsilerde yalancı pozitiflik görülebilir (21).

\section{Kemoradyoterapi Sonrası Evrelemede EUS}

Özofagus kanserlerinde kemoradyoterapi sonrası evrelemede EUS; tümör ile ödem, fibrozis, inflamasyon ve nekroz ayrımını yapamadığından tanısal doğruluk oranı düşük olup ortalama \%40'dır (\%25-82) (22, 23). Bu nedenlerden dolayı genelde olduğundan daha ileri evre rapor edilirler. Yine de kemoradyoterapi sonrası tümör kalınlığının ölçümünde başlangıca göre $>\% 50$ azalma gözlenen vakalarda survinin iyi olduğu üzerinde durulmaktadır (22, 24-27). MD Anderson Kanser Merkezinde 2006-2009 arası özofagus kanseri tanısı alan ve kemoradyoterapi (KT) sonrası opere edilen 146 hastanın verileri retrospektif olarak değerlendirildi. Bu hastalardan 102'sinin kemoradyoterapi öncesi ve KT sonrasinda EUS ile evreleme raporlanı mevcuttu. KT sonrası EUS evresinin 81 
hastada değişmediği, 18'inde azaldığı ve 3 hastada ise arttığ görüldü. 102 hastanın operasyon sonrası histopatolojik değerlendirmesinde 27 olguda rezeksiyon materyalinde tümör hücresi saptanmaz iken; bu hastaların tamamında EUS evresi Tl ve üzeriydi. Bu çalışmada KT sonrası EUS ile yeniden evreleme sonuçlarıla histopatolojik değerlendirme arasında ilişki gözlenmedi ve EUS'un spesifitesi çok düşük bulundu (28). Lenf nodu evrelemesinde de KT sonrası EUS'un tanısal doğruluk oranı düşüktür (\%38-73). Prospektif yapılan ve fazla sayıda hasta içeren bir çalışmada KT sonrası EUS ile lenf nodu değerlendirilmesinin tanısal doğruluk oranı \%60, sensitivitesi \%68, spesifitesi ise \%42 rapor edilmiştir (22). BT / PET-BT ile EUS'un KT sonrası lenf nodu evrelemesindeki doğruluk oranları benzer bulunmuştur $(26,27)$. Eğer lenf nodu evrelemesinde EUS işlemine EUS-FNA ilave edilirse tanısal doğruluk oranının arttığı gözlenmiştir.

\section{Darlıkla Seyreden Özofagus Kanserlerinde EUS}

Özofagus kanserli hastalarm \%25-38'inde standart endoskopların geçisine izin vermeyen tam darlık mevcuttur. Bu vakalara: 1. Önce buji ya da balon ile dilatasyon işlemi, arkasından EUS yapilabilir. Ancak bu olgularda \%25 perforasyon komplikasyonu bildirilmiştir (29). Son zamanlarda stenotik olguların daha ileri evrede olduğu dilatasyon işlemi sonrasında EUS yapmanın hastanın survine katkısı olmadığı rapor edilmiştir (30). 2. Darlık alanı üzerinden evreleme yapılabilir, ancak bu yöntemle de tümörün olduğundan daha düşük evre rapor edilme ihtimali yüksektir ve lenf nodlarının evrelemesi tam olarak yapilamaz. 3. Daha ince endoskoplar (slim skop) veya endoskop kanalından geçen mini problarla evrelemedir. Bu yöntem bir çok merkez tarafından yaygın olarak kullanılır. Yapmış olduğumuz bir çalışmada özofagus kanseri ve ona bağlı darlık nedeniyle EUS cihazı geçmeyen 50 hasta ile kontrol grubu olarak darlığı olmayan 50 özofagus kanseri olgusu alındı ve verileri retrospektif tarandı. Tümöre bağlı darlığı olan hastalarda survi ve ona etki eden faktörler araştırıldı. Tümöre bağlı darlığı olan 50 hastanın 33'ünün (\%66) evrelemesi mini probla, 14'ünün standart EUS cihazı darlık üzerinden ve 3 (\%6) tanesinin ise dilatasyon sonrası standart EUS ile evrelemesi yapılmıştı. Ortalama survi darlığı olan hastalarda 28 ay; darlık olmayan hastalarda 57 ay izlendi $(\mathrm{p}=0.0027)$. Darlik olan grupta kanser nüksü ve yan etkileri daha sıktı $(\mathrm{p}<0.0001)$. Ayrica ortalama survi histopatolojik inceleme adenokanser rapor edilenlerde 48 ay, yassı hücreli kanseri olanlarda ise 15 ay saptandı (0.0236) (31).

\section{B. MIIDE KANSERII EVRELEMESİNDE EUS}

Mide kanserlerinin \%90'dan fazlası adenokanser olup genellikle tanı anında ileri evredirler. 5 yıllık survi bu grupta yaklaşık \%15-20'dir. Eğer kanser midede sınırlı ise 5 yıllık survi \%55'lere çıkar $(2,3)$. Mide kanserlerinde EUS kullanımının esas amacı komşu organlara yayılımı, mide çevresinde serbest asit olup olmadığını belirlemek, asit varsa buradan EUS-FNA ile örnek almak ve en önemlisi optimal tedavi şeklinin (endoskopik tedavi, cerrahi veya kemoradyoterapi) belirlenmesine yardımcı olmaktır (32).

\section{Erken Mide Kanserlerinde EUS}

EUS, erken mide kanserlerinin evrelemesinde de yaygin olarak kullanılır. Erken mide kanserlerine özellikle Asya ve uzak doğuda tarama programları sırasında sık rastlanır. Bu lezyonlar mukozada sinırlı ve lenf nodu tutulumu yok ise endoskopik mukozal rezeksiyon yapilır. Erken mide kanserlerinin evrelemesinde 7.5/12 MHz ekoendoskoplar yaklaşı \%25 olgunun evrelemesinde yetersiz kalır. Bu nedenle mukoza ve submukoza ayrımını yapabilen yüksek frekanslı (20-30 MHz) problar kullanılır. Yüksek frekansli mini probların submukozal invazyonu göstermede sensitivitesi \%71-95, spesifitesi ise \%74-91'dir. Eğer tümör boyutu 3 cm'den büyük ve histopatoloji sonucu kötü diferansiye ise tanısal doğruluk oranı negatif yönde etkilenir (32). Erken mide kanserinde endoskopik görünüm ile EUS'un tanısal doğruluğu arasında da ilişki söz konusudur. Özellikle deprese tip lezyonlarda (Tip IIc veya Tip IIc + Tip III) fibrozis ile tümör ayrımı yapılamadığından tanısal doğruluk oranı düşüktür. Yasuda ve arkadaşlarının bir çalısmasında Tip I, Tip IIa, Tip Ila + Tip IIc, Tip IIc ve TipIIc +Tip III erken kanserler için tanısal doğruluk oranları sıraslyla \%83.3, \%86.2, \%79.2, \%76.6 ve \%72.3 bildirilmiştir (33). Son yıllarda erken mide kanserlerinin mukozal-submukozal ayrımını göstermede üç boyutlu EUS yöntemi de kullanılmaktadır. Bu yöntem endoskopik tedavi seçeneklerinden endoskopik mukozal rezeksiyon (EMR) veya endoskopik submukozal diseksiyon (ESD) endikasyonunu belirlemeye yardımcı olur (34). Kida ve arkadaşları üç boyutlu EUS yöntemiyle yaptıkları bir çalışmada mukozal kanserlerin ayrıt edilmesinde tanısal doğruluk oranını \%96 bildirmişlerdir (35).

\section{İleri Evre Mide Kanserlerinde EUS}

1993-2006 arası 22 çalışmanın verilerine dayanarak EUS'un mide kanseri evrelemesinde sensitivitesi \%82-99 bildirilmiştir. Ancak tanısal doğruluk oranı T2 evre olgularda daha düşüktür (36). Buradaki esas problem EUS'un subserozal (T2) ve serozal (T3) infiltrasyon ayrımını yapamamasıdır. Başka bir çalışmada ise mide kanseri evrelemesinde EUS'un tanısal doğruluk oranı, bütün evreler ile T1, T2, T3 ve T4 evreleri için sırasıly \%77-88, \%79-100, \%63.3-73.9, \%85.7-95 ve \%72.7-100 rapor edilmiştir. Aynı çalışmada lenf nodu evrelemesi için tanısal doğruluk oranı \%65-80, sensitivite: \%66.7\%91; spesifite ise \%73.7-84 bulunmuş (37). Mide kanserlerinde yapılan EUS ile lokal evreleme işlemi en az \%30 vakada tedaviyi değiştirmekte ve sinırlı rezeksiyonlar yapılmaktadır (37). Mide kanserlerinde de TNM sinıflaması kullanılmakla birlikte, 1997 sonrası lenf nodu evrelemesi değişmiş, lenf 
nodlarının lokalizasyonundan çok; lenf nodu sayısı üzerinde durulmuş ve NO, N1, N2, N3 şeklinde düzenlenmiştir. Bir meta analiz çalışmasına göre bölgesel lenf nodu evrelemesinde N1 ve N2 için sensitivite $\% 58$ ve $\% 65$, spesifite ise sırasiyla \%87 ve \%92 rapor edilmiştir (36). Helikal BT ve multidedektor BT ile EUS'in doğrudan karşılaştırıldığı çalışmalardan sadece bir tanesinde T evrelemesinde EUS, helikal BT'den üstün bulunmuştur. Lenf nodu evrelemesinde ise bu iki teknikle EUS arasında fark görülmemiştir $(38,39)$. Bugün için mide kanserlerinde PET'in lenf nodu metastazını göstermede en duyarlı yöntem olduğu ve ilk tercih olarak kullanılması gerektiği vurgulanmaktadır (40).

Mide kanserlerinde cerrahi sonrası anastamoz nüksü Tl ve T2 evrede: \%5; T3 ve T4 evrede ise yaklassık \% 77'dir. Endoskopik muayenede anastomoz bölgesinin nodüler olması ve yüzeydeki düzensizlik nüks olabileceğini akla getirmelidir. Anastomoz alanlarındaki nükslerin değerlendirilmesinde EUS'un sensitivite:\%95, spesifitesi ise \%80'dir ve bu alandaki duvar kalınlığının > 7 mm olması da anlamlıdır (41).

Mide kanserlerinde KT sonrası EUS ile yeniden evrelemenin özofagus kanserlerindeki gibi tanısal doğruluk oranı düşüktür. Bir çalışmada T evrelemesi için tanısal doğruluk oranı \%47, N evlemesi için ise \%39 bildirilmiştir. Ancak bu çalışmada EUS ile tümör evresinde belirgin gerilemenin varlığ multivariyant analizde survi üzerine etkili bulunmuştur (42).

\section{Mide Lenfomalarının Evrelemesinde EUS}

GIS lenfomalarının yaklaşık \%70'i mide, \%20-30 kadarı ince barsak ve \%2'si kalın barsak yerleşimlidir. EUS'un mide lenfomalarında kullanım amacı: lokal evreleme yapmak, şüpheli lenf nodlarından biyopsi almak ve özellikle düşük gradeli lenfomalarda (MALTOMA gibi) tedavi sonrası yanıtı değerlendirmektir. MALT lenfoma etiyolojisinde Helikobakter pylori enfeksiyonunun rolü vardır. Bu enfeksiyonun eradikasyonu ile MALT lenfomanın gerilediği gösterilmiştir. MALT lenfoma tanısı alan hastalarda eğer hastalık mukoza ve submukozada sınırlı ise antibiyotik tedavisine yanıt verir. Submukozadan daha derinlere invazyon söz konusu ise kemoterapi önerilir (36, 37). Bu yüzden MALT lenfomanın evrelemesinde EUS yaygın olarak kullanılır. Literatüre baktığımızda lenfomaların evrelemesinde EUS kullanımıyla ilgili hasta sayısı oldukça sınırlıdır. Hasta sayısı 11 ile 44 arasında değişen 4 ayrı çalışmada T evrelemesi için tanısal doğruluk oranı \%80-91, ekstra nodal tutulumun göstergesi olan lenf nodu varlığı için ise oran \%7790 bildirilmiştir (1).

\section{KOLOREKTAL KANSERLERINN EVRELEMESINDE EUS}

Rektum kanserlerinde prognoz, operasyon sonrası nüks ve yapılacak tedavi türü tamamen tümörün rektum duvarına yayllımına, lenf nodu ve komşu organlara metastaz olup olma-
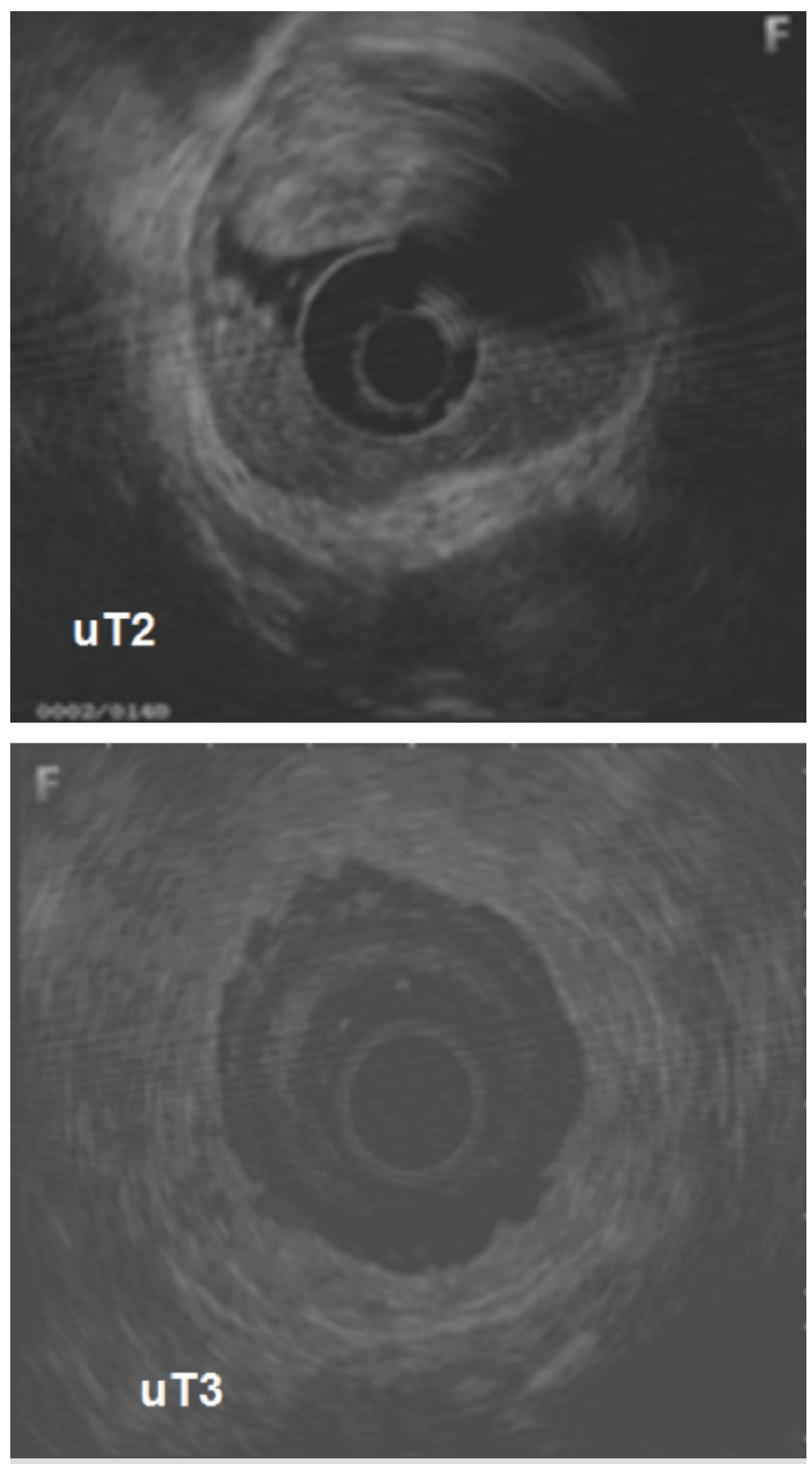

Figür 3. Rektum kanserinin EUS ile evreleme görüntüleri uT2: muskularis propria invazyonu, uT3: Perirektal yag doku invazyonu.

masına göre değişir. EUS ile evreleme için TNM sinıflaması kullanılır (Figür 3). Rektum kanserlerinde BT ile uzak metastaz ekarte edildikten sonra EUS ile lokal evreleme yapılır. Rijit rektal ultrasonografi (USG) cihazları yanında fleksibıl olan ekoendoskoplar da kullanılır. Fleksibıl cihazların avantaji: direkt tümörün görüntülenebilmesi ve iliyak lenf nodlarının değerlendirilmesidir. Hastalara işlem öncesi lavman veya normal kolonoskopi hazırlığı verilir. Derin sedasyona gerek yoktur. EUS öncesi rektosigmoidoskop ile inceleme yapilarak lezyonun boyutu, lokalizasyonu ve kolon temizliğinin yeterli olup olmadığı değerlendirilir. Takiben radial ekoendoskop ile girilerek tümörün rektum duvarına invazyon derinliği, perirektal yağ dokuya invazyon, mesane, prostat, vezikülo-seminalis, vajina ve anal sfinkter gibi komşu organlara yayılım değerlendirilir. Lenf nodu evrelemesi için ekoendoskop ile anal 
kanaldan itibaren $25 \mathrm{~cm}$ ileriye gidilir, hava aspire edildikten sonra iliyak damarlar görüntülenerek iliak lenf nodları değerlendirilir. Rektum tümörlerinin eko paterni genellikle hipoekoiktir. Muskularis proprianın tutulumu T2, perirektal yağ doku invazyonu ise T3'dür (Figür 4).

Rektum kanserlerinin evrelemesinde EUS'in tanısal doğruluk oranı T evrelemesi için \% 75-92 olup; \%22 oranında olduğundan daha ileri evreleme söz konusudur (43). Özofagus kanserlerinde olduğu gibi rektum kanserlerinin evrelemesinde de EUS inflamasyon ile tümörü ayıramaz. Özellikle T2 tümörler T3 gibi yorumlanabilir. Lenf nodlarının da morfolojik olarak benign-malign ayrımı güçlük yaratır. Yapılan çalışmalarda lokal evrelemede EUS, BT'den üstün bulunurken; MRI ve EUS'un çalışmalarda tanısal doğruluk oranları benzer bulunmuştur. Bugün için EUS+MRI rektum kanserlerinde $\mathrm{T}$ ve $\mathrm{N}$ evrelemesinde en yaygın kullanılan tekniklerdir. Bir çalışmada tek başına BT ile tedavi planı yapılan hastalara EUS ilave edildiğinde hastaların \%38'inde tedavi şekli değișmiş, aynı hastalara EUS-FNA eklendiğinde ise tedavi şeklindeki değişikliğin \%19 daha arttığı görülmüștür (43). Müller ve ark. başka bir çalışmada rektum kanserlerinin evrelemesinde EUS, BT ve MRI tekniklerini karṣlaștırmıș ve T evrelemesi için tanısal doğruluk oranları sırasıyla \%80-95, \%65-75 ve \%75-85; $\mathrm{N}$ evrelemesi için \%70-75, \%55-65 ve \%60-65 rapor etmişlerdir. Çalışmanın tartışma kısmında T evrelemesinde EUS ile MRI'ın benzer olduğu; $N$ evrelemesinde ise EUS tekniğinin BT ve MRI'dan üstün olduğunu vurgulamışlardır (44).

Malign lenf nodları EUS incelemesi sırasında genellikle yuvarlak, düzgün kenarl, 10 mm'den büyük ve hipoekoik karakterde görülür. Ancak perirektal lenf nodları benign durumlarda çok nadir görülür. Bu nedenle rektum kanserlerinde $<10$ $\mathrm{mm}$ lenf nodu saptanması halinde malign olma özelliği akla gelmelidir ki; bu boyuttaki lenf bezlerinde \%45-70 tümör infiltrasyonu bildirilmiştir (45). Lenf nodu evrelemesinde EUS'un MRI'dan üstün olduğunu gösteren yayınlar vardır

\section{KAYNAKLAR}

1. Fischbach W, Al-Taie O. Staging role of EUS. Best Pract Res Clin Gastroenterol 2010; 24: 13-7.

2. Greene FL, Page DL, Fleming ID, et al, editors. AJCC cancer staging manual, $6^{\text {th }}$ edition. New York: Springer, 2002.

3. Sobin LH, Wittekind CL, editors. TNM classification of malignant tumors, $6^{\text {th }}$ edition. New York: John Wiley \& Sons, 2002.

4. Veuillez V, Rougier P, Seitz JF. The multidisciplinary management of gastrointestinal cancer. Multimodal treatment of oesophageal cancer. Best Pract Res Clin Gastroenterol 2007; 21: 947-63.

5. Siemsen M, Svendsen LB, Knigge U, et al. A prospective randomized comparison of curved array and radial echoendoscopy in patients with esophageal cancer. Gastrointest Endosc 2003; 58: 671-6.

6. Matthes K, Bounds BC, Collier K, et al. EUS staging of upper GI malignancies: results of a prospective randomized trial. Gastrointest Endosc 2006; 64: 496-502.
(46). EUS, BT ve MRI gibi üç farklı tekniğin lenf nodu evrelemesindeki tanısal doğruluk oranları karşılaştırılmış ve sırasiyla \%61-82, \%56-79, \%57-85 bildirilmiștir (47, 48). Son ylllarda yüksek çözünürlüklü 3 boyutlu EUS cihazların kullanımıyla rektum kanserlerinin evrelemesindeki doğruluk oranları T evrelemesi için \% $75^{\prime}$ den \%95'e, lenf nodu evrelemesi de \%65'den \%80'lere çıkmıştır.

Bugün için ileri evre rektum kanserlerinde operasyon öncesi kemoterapi ve radyoterapi lokal nüksü azaltır ve survi uzatır. Kemoradyoterapiye bağlı oluşan ödem, fibrozis ve inflamasyona bağlı kemoterapi sonrası EUS ile yeniden evrelemenin tanısal doğruluk oranı olup \%48-75 arasında değişir. Bu grup hastalarda tümörün olduğundan daha düşük evrelenmesi \%7-14, daha yüksek evrelenme ise \%18-38'dir. Lenf nodu evrelemesi doğruluk oranı ise \%68-80'dir (49-51). EUS, nüks rektum kanseri tanısı ve evrelemesinde de kullanılmaktadır. Rektum kanserlerinde küratif rezeksiyon sonrası lokal nüks ilk 1-2 yllda \%10-15'dir. Radiyal EUS cihazı lokal nüksü göstermede $>\% 90$ sensitif bir yöntemdir. Bir çalışmada nüks rektum kanserini göstermede EUS'un tanısal doğruluğu \%75, EUS-FNA tekniğininki ise \%92 rapor edilmiştir. Ayrıca bu çalışmada EUS’un sensitivite ve spesifitesi BT ve BT eşliğinde yapılan biyopsi yöntemlerinden üstün bulunmuştur (44).

Kolon kanseri evrelemesinde standart radial ve lineer cihazların çok rijit olması nedeniyle kolonoskobun biyopsi kanalından geçebilen yüksek frekanslı mini problar kullanılır. Bu yöntemin tanısal doğruluk oranı kolon kanserlerinde $\mathrm{T}$ evrelemesi için \%87-94, N evrelemesi için ise \%80-84 rapor edilmiştir (52)

Sonuç olarak, endoskopik ultrasonografi gastrointestinal sistem kanserlerinin lokal evrelemesinde etkin ve güvenilir bir yöntemdir. Hastalığın prognozu hakkında bilgi verir, tedavi yönteminin seçimine yardımcı olur. Ayrıca lenf bezlerinden yapılan biyopsi tanısal doğruluk oranlarını artırarak gereksiz ameliyat oranını azaltır.

7. Pech O, Günter E, Ell C. Endosonography of high-grade intra-epithelial neoplasia/early cancer. Best Pract Res Clin Gastroenterol 2009; 23: 63947.

8. Hasegawa N, Niwa Y, Arisawa T, et al. Preoperative staging of superficial esophageal carcinoma: comparison of an ultrasound probe and standard endoscopic ultrasonography. Gastrointest Endosc 1996; 44: 388-93.

9. Kawano T, Ohshima M, Iwai T. Early esophageal carcinoma: endoscopic ultrasonography using the sonoprobe. Abdom Imaging 2003; 28: 477 85 .

10. Murata Y, Suzuki S, Ohta M, et al. Small ultrasonic probes for determination of the depth of superficial esophageal cancer.Gastrointest Endosc 1996; 44: 23-8

11. Chemaly M, Scalone O, Durivage G, et al. Miniprobe EUS in the pretherapeutic assessment of early esophageal neoplasia. Endoscopy 2008; 40: $2-6$ 
12. Rampado S, Bocus P, Battaglia G, et al. Endoscopic ultrasound: accuracy in staging superficial carcinomas of the esophagus. Ann Thorac Surg 2008; 85: 251-6.

13. May A, Gunter E, Roth F, et al. Accuracy of staging in early oesophageal cancer using high resolution endoscopy and high resolution endosonography: a comparative, prospective, and blinded trial. Gut 2004; 53 : 634-40.

14. Larghi A, Lightdale CJ, Memeo L, et al. EUS followed by EMR for staging of high-grade dysplasia and early cancer in Barrett's esophagus. Gastrointest Endosc 2005; 62: 16-23.

15. Esaki M, Matsumoto T, Moriyama T, et al. Probe EUS for the diagnosis of invasion depth in superficial esophageal cancer: a comparison between a jelly-filled method and a water-filled balloon method. Gastrointest Endosc 2006; 63: 389-95.

16. van Vliet EP, Heijenbrok-Kal MH, Hunink MG, et al. Staging investigations for oesophageal cancer: a meta-analysis. Br J Cancer 2008; 98: 547-57.

17. Catalano MF, Sivak MV Jr, Rice T, et al. Endosonographic features predictive of lymph node metastasis. Gastrointest Endosc 1994; 40: 442-6.

18. Bhutani, MS, Hawes, RH \& Hoffman, BJ. A comparison of the accuracy of echo features during endoscopic ultrasound (EUS) and EUS-guided fine-needle aspiration for diagnosis of malignant lymph node invasion. Gastrointest Endosc 1997; 45: 474-9.

19. Puli SR, Reddy JB, Bechtold ML, et al. Staging accuracy of esophageal cancer by endoscopic ultrasound: a meta-analysis and systematic review. World J Gastroenterol 2008; 14: 1479-90.

20. van Vliet EP, Eijkemans MJ, Kuipers EJ, et al. Publication bias does not play a role in the reporting of the results of endoscopic ultrasound staging of upper gastrointestinal cancers. Endoscopy 2007; 39: 325-32.

21. Vazquez-Sequeiros E, Wiersema MJ, Clain JE et al. Impact of lymph node staging on therapy of esophageal carcinoma. Gastroenterology 2003; 125: 1626-35.

22. Lightdale CJ, Kulkarni KG. Role of endoscopic ultrasonography in the staging and follow-up of esophageal cancer. J Clin Oncol 2005; 23: 4483-9.

23. Romagnuolo J, Scott J, Hawes RH, et al. Helical CT versus EUS with fine needle aspiration for celiac nodal assessment in patients with esophageal cancer. Gastrointest Endosc 2002;55:648-54.

24. Swisher SG, Maish M, Erasmus JJ, et al. Utility of PET, CT, and EUS to identify pathologic responders in esophageal cancer. Ann Thorac Surg 2004; 78: 1152-60

25. Kalha I, Kaw M, Fukami N, et al. The accuracy of endoscopic ultrasound for restaging esophageal carcinoma after chemoradiation therapy. Cancer 2004; 101: 940-7.

26. Cerfolio RJ, Bryant AS, Ohja B, et al. The accuracy of endoscopic ultrasonography with fine-needle aspiration, integrated positron emission tomography with computed tomography, and computed tomography in restaging patients with esophageal cancer after neoadjuvant chemoradiotherapy. J Thorac Cardiovasc Surg 2005; 129: 1232-41.

27. Ribeiro A, Franceschi D, Parra J, et al. Endoscopic ultrasound restaging after neoadjuvant chemotherapy in esophageal cancer. Am J Gastroenterol 2006; 101: 1216-21.

28. Bektas M, Oruc N, Qiao W, et al. Which technique predicts histopathologic regression after neoadjuvant therapy for esophageal cancer? DDW 2010, May 1-5, 2010: New Orleans W1882 (abstract).

29. Catalano MF, Van Dam J, Sivak MV Jr. Malignant esophageal strictures: staging accuracy of endoscopic ultrasonography. Gastrointest Endosc 1995; 41: 535-9.

30. Catalano MF, Alcocer E, Chak A. et al. Evaluation of metastatic celiac axis lymph nodes in patients with esophageal carcinoma: accuracy of EUS. Gastrointest Endosc 1999; 50: 352-6

31. Raju RP, Jaganmohan S, Bektas M, et 1. Prognostic implications of high grade malignant esophageal strictures in esophageal cancer. DDW 2010, May 1-5, 2010: New Orleans S 1501 (abstract).

32. Yasuda, K. EUS in the detection of early gastric cancer. Gastrointest Endosc. 2002 Oct; 56(4 Suppl): S68-75.
33. Yasuda K, Nakajima M, Kawai K. Endoscopic diagnosis and treatment of early gastric cancer using endoscopic ultrasonography (EUS). Gastrointest Endosc Clin North Am 1992; 2: 495-507.

34. Ichikawa T, Kudo M, Matsui S, et al. Endoscopic ultrasonography with three miniature probes of different frequency is an accurate diagnostic tool for endoscopic submucosal dissection. Hepatogastroenterology 2007; 54: 325-8.

35. Kida M, Kikuchi H, Ikeda H, et al. Diagnosis of gastric cancer invasion with three-dimensional endoscopic ultrasonography, especially in cases with "SM1" invasion. Stomach and Intesine 2007; 42; 88-98.

36. Puli SR, Batapati Krishna Reddy J, Bechtold ML, et al. How good is endoscopic ultrasound for TNM staging of gastric cancers? A meta-analysis and systematic review. World J Gastroenterol 2008; 14: 4011-9.

37. Fujino Y, Nagata Y, Ogino K, Watahiki H. Evaluation of endoscopic ultrasonography as an indicator for surgical treatment of gastric cancer. J Gastroenterol Hepatol 1999; 14: 540-6.

38. Habermann CR, Weiss F, Riecken R, et al. Preoperative staging of gastric adenocarcinoma: comparison of helical CT and endoscopic US. Radiology 2004; 230: 465-71

39. Bhandari S, Shim CS, Kim JH, et al. Usefulness of three-dimensional, multidetector row CT (virtual gastroscopy and multiplanar reconstruction) in the evaluation of gastric cancer: a comparison with conventional endoscopy, EUS, and histopathology. Gastrointest Endosc 2004; 59: 619-26.

40. Kwee RM, Kwee TC. Imaging in local staging of gastric cancer: a systematic review. J Clin Oncol 2007; 25: 2107-16.

41. Lightdale CJ, Botet JF, Kelsen DP, et al. Diagnosis of recurrent upper gastrointestinal cancer at the surgical anastomosis by endoscopic ultrasound. Gastrointest Endosc 1989; 35: 407-12.

42. Park SR, Lee JS, Kim CG, et al. Endoscopic ultrasound and computed tomography in restaging and predicting prognosis after neoadjuvant chemotherapy in patients with locally advanced gastric cancer. Cancer 2008; 112: 2368-76.

43. Shami VM, Parmar KS, Waxman I. Clinical impact of endoscopic ultrasound and endoscopic ultrasound-guided fine-needle aspiration in the management of rectal carcinoma. Dis Colon Rectum 2004; 47: 59-65.

44. Müller C, Kähler G, Scheele J. Endosonographic examination of gastrointestinal anastomoses with suspected locoregional tumor recurrence. Surg Endosc 2000; 14: 45-50.

45. Beynon J, Mortensen NJ, Foy DM, et al. Preoperative assessment of mesorectal lymph node involvement in rectal cancer. Br J Surg 1989; 76: 276-9.

46. Thaler W, Watzka S, Martin F, et al. Preoperative staging of rectal cancer by endoluminal ultrasound vs. magnetic resonance imaging. Preliminary results of a prospective, comparative study. Dis Colon Rectum 1994; 37: 1189-93.

47. Fuchsjager MH, Maier AG, Schima W, et al. Comparison of transrectal sonography and double-contrast MR imaging when staging rectal cancer. Am J Roentgenol 2003; 181: 421-7.

48. Ferri M, Laghi A, Mingazzini P, et al. Pre-operative assessment of extramural invasion and sphincteral involvement in rectal cancer by magnetic resonance imaging with phased-array coil. Colorectal Dis 2005; 7: 387-93.

49. Radovanovic Z, Breberina M, Petrovic T, et al. Accuracy of endorectal ultrasonography in staging locally advanced rectal cancer after preoperative chemoradiation. Surg Endosc 2008; 22: 2412-5.

50. Vanagunas A, Lin DE, Stryker SJ. Accuracy of endoscopic ultrasound for restaging rectal cancer following neoadjuvant chemoradiation therapy. Am J Gastroenterol 2004; 99: 109-12.

51. Maor Y, Nadler M, Barshack I, et al. Endoscopic ultrasound staging of rectal cancer: diagnostic value before and following chemoradiation. J Gastroenterol Hepatol 2006; 21: 454-8.

52. Hünerbein M, Handke T, Ulmer C, Schlag PM. Impact of miniprobe ultrasonography on planning of minimally invasive surgery for gastric and colonic tumors. Surg Endosc 2004;18: 601-5. 